\title{
KAJIAN PENERAPAN STANDAR TAHAN GEMPA PADA PEMERIKSAAN STRUKTUR GEDUNG TERBANGUN
}

\section{APPLICATION ASSESSMENT OF THE SEISMIC RESISTANT STANDARD ON THE EVALUATION OF EXISTING STRUCTURES}

\author{
Mulyo Harris Pradono \\ Pusat Teknologi Reduksi Risiko Bencana, Kedeputian Bidang Teknologi Pengembangan Sumberdaya \\ Alam, Badan Pengkajian dan Penerapan Teknologi, Gedung 820, Geostech, Kawasan PUSPIPTEK, \\ Serpong, Tangerang 15314, telepon: (021) 75791378 \\ e-mail: mulyo.harris@bppt.go.id
}

\begin{abstract}
In the earthquake resistant building design standard, earthquake-safe buildings must meet several criteria that can be assessed when the building has been built. Several criteria can be examined by conducting a detailed review of the building. There are three criteria that can be used to check whether an existing structure is in accordance with the required standards. The criteria are column dimensions, column capacity, and period of structural vibration. By reviewing the compressive strength of concrete, reinforcement in columns and beams, and numerical modeling the structure of buildings, the three criteria above can be assessed and compared to the requirements in the earthquake resistant building design standards. In this paper, an assessment activity of a multi-storey building to determine the suitability of the building structure with the requirements in the standard is presented.
\end{abstract}

Keywords: seismic resistant standard, building, assessment, application of standard

\begin{abstract}
ABSTRAK
Di dalam standar perencanaan bangunan tahan gempa, disebutkan bahwa gedung yang aman gempa harus memenuhi beberapa kriteria yang dapat dikaji saat gedung sudah dibangun. Beberapa kriteria dapat diperiksa dengan melakukan kajian detil pada gedung. Ada tiga kriteria yang dapat digunakan untuk memeriksa apakah suatu struktur terbangun sudah sesuai dengan standar yang dipersyaratkan. Kriteria itu adalah dimensi kolom, kapasitas kolom, dan periode getar struktur. Dengan melakukan kaji kuat tekan beton, kaji tulangan dalam kolom dan balok, serta pemodelan numerik struktur gedung, maka ketiga kriteria di atas dapat dikaji dan dibandingkan dengan persyaratan di dalam standar perencanaan bangunan tahan gempa. Dalam makalah ini disampaikan kegiatan kajian pada sebuah gedung bertingkat untuk mengetahui kesesuaian struktur gedung dengan persyaratan yang ada dalam standar.
\end{abstract}

Kata kunci: standar tahan gempa, bangunan gedung, kajian, penerapan standar.

\section{PENDAHULUAN}

\section{$1.1 \quad$ Latar Belakang}

Gedung bertingkat yang sudah terbangun, umumnya sudah melalui proses yang panjang terutama dari segi desain strukturnya. Tujuannya agar desain menghasilkan gedung yang aman yang sesuai dengan standar yang berlaku. Proses ini meliputi kajian terhadap desain struktur sampai dengan kajian terhadap desain lainnya.

Untuk DKI Jakarta, ada Tim Ahli Bangunan Gedung (TABG) yang terdiri dari unsur perguruan tinggi, asosiasi profesi dan masyarakat ahli. Para profesor, doktor, dan insinyur dalam TABG ini mempunyai fungsi untuk memberikan nasihat soal bangunan, khususnya gedung dengan ketinggian lebih dari delapan lantai, bangunan pelestarian, rumah sakit, dan lain-lain. Hanya saja, TABG tidak berkuasa untuk mengawasi pelaksanaannya. TABG hanya sebatas memberikan pertimbangan sebagai penasihat profesional, namun tidak bisa mengawasi pelaksanaannya (Detik News, 2014).

Dilihat dari kenyataan di atas, perlu adanya kajian-kajian terhadap struktur gedung yang sudah terbangun apakah masih sesuai dengan standar yang berlaku. Di dalam makalah ini akan disampaikan metode kajian 
yang dapat diterapkan untuk mengkaji keandalan suatu gedung ditinjau dari keamanan terhadap ancaman gempabumi.

Beberapa metode untuk mengkaji struktur gedung yang sudah berdiri sudah disajikan pada beberapa literatur. Salah satunya adalah mengenai evaluasi ketahanan gempa struktur gedung di Jakarta berdasarkan SNI 03-1726-2012 (Fauzan et al., 2016).

Di dalam literatur tersebut, gedung yang menjadi objek ini diajukan untuk mendapatkan Sertifikat Laik Fungsi (SLF) Bangunan Gedung sesuai Peraturan Menteri Pekerjaan Umum Nomor 25/PRT/M/2007 (Departemen Pekerjaan Umum, 2007). Bangunan gedung yang memiliki jumlah lantai lebih dari 2 dapat mengajukan sertifikasi kelaikan fungsi bangunan gedung setiap 5 tahun sekali. Gedung tersebut akan dievaluasi oleh tim ahli bangunan gedung (TABG) sepanjang gedung tersebut berdiri agar diketahui kondisi kinerja struktur gedung tersebut untuk masa sekarang. Hal inilah yang mendasari perlu dilakukannya penelitian tentang evaluasi kinerja struktur gedung-gedung bertingkat tinggi di Jakarta yang dibangun. Tujuan dari metode ini adalah mengetahui kinerja batas ultimat struktur gedung kajian berdasarkan pembebanan gempa SNI 03-1726-2012. Data yang digunakan dalam kajian pada literatur tersebut adalah gambar As Built Drawing, gambar arsitektur, dan referensi tentang peta kelas situs jenis tanah. Pengecekan kondisi kini gedung dilakukan melalui pengamatan visual dan Hammer Test. Metoda ini menghasilkan kesimpulan bahwa gedung yang dikaji yang berlokasi di Jakarta tersebut belum memenuhi syarat (aman) terhadap kinerja batas simpangan antar lantai tingkat yang diizinkan.

Literatur berikutnya membahas mengenai audit kekuatan struktur dan perkuatan struktur pasca gempa (Madutujuh et al., 2013). Di dalam literatur tersebut, dibahas beberapa metode audit struktur dan metode perkuatan pasca kejadian gempa. Struktur yang tidak memenuhi syarat kekuatan ada yang masih dapat diperkuat sampai batas tertentu asalkan dilakukan dengan metode yang sesuai. Metode yang disampaikan adalah:

- perkuatan dengan fiber wrap

- perkuatan dengan lapisan beton baru

- perkuatan dengan pelat dan profil baja.

Semua metode di atas digunakan untuk memperkuat kolom, pelat, dan balok beton sampai pada tingkatan tertentu.

Di luar negeri, metode yang digunakan untuk kajian kerentanan gedung juga banyak distandarkan. Standar yang pertama, FEMA 154, Rapid Visual Screening of Buildings for Potential Seismic Hazards, membahas mengenai metode kaji kerentanan gedung berdasarkan metode visual. Di dalam standar ini digunakan formulir standard untuk daerah high seismicity hingga low seismicity.

Selain metode yang menggunakan cara visual, ada juga metode yang menggunakan alat untuk kajian kerentanan gedung bertingkat. FEMA-310, Handbook for the Seismic Evaluation of Buildings, merupakan metode yang menerapkan cara yang paling sederhana sampai cara yang paling detil. Tujuannya adalah cara yang paling sederhana digunakan untuk mengkaji gedung dengan tingkat kesulitan kaji yang paling sederhana. Apabila hasil dari kajian sederhana ini masih meragukan, maka dilakukan kaji pada tahap yang lebih detil.

$\mathrm{Di}$ dalam makalah ini, akan disampaikan metode pemeriksaan yang relatif detil, dan juga ditambahkan metode-metode yang diambil dari SNI 1726:2012 dan SNI 2847:2013, untuk menilai apakah struktur yang dikaji sesuai dengan SNI tersebut atau tidak. SNI 17262012 untuk menilai struktur dari segi batas waktu getar alami gedung dan SNI 28472013 dari segi batas kapasitas kolom dibanding kapasitas balok serta dimensi kolom dihubungkan dengan dimensi tulangan balok yang merangka pada kolom tersebut.

\subsection{Tujuan Penelitian}

Penelitian ini bertujuan untuk mendapatkan metode kajian yang paling sesuai untuk bangunan gedung agar mudah dilakukan dan sesuai sasaran. Metode yang diusulkan adalah:

1. Kajian terhadap gambar As Built Drawing struktur gedung (gambar harus diadakan oleh pengelola gedung).

2. Kajian terhadap dimensi struktur gedung di lapangan (kolom, balok, pelat lantai, dan dinding struktur).

3. Kajian terhadap material struktur di lapangan (jika beton bertulang):
a. Kuat tekan beton
b. Dimensi baja tulangan
c. Kuat tarik baja tulangan

4. Analisis ragam getar dan waktu getar alami struktur gedung dari data dimensi struktur.

5. Analisis kekuatan kolom dan balok sesuai standar yang berlaku.

Metode di atas diaplikasikan pada struktur gedung yang sudah terbangun untuk menguji kesesuaian dengan tujuan penelitian. 


\subsection{Ruang Lingkup}

Ruang lingkup gedung yang dikaji dalam makalah ini adalah gedung dengan struktur beton bertulang. Hal ini disebabkan struktur beton bertulang merupakan struktur yang paling banyak dipakai, dan pada saat yang bersamaan merupakan struktur yang paling sulit dikaji. Sulit dalam hal kuat tekan beton sangat bervariasi bahkan pada satu komponen saja, misalnya kolom. Kemudian, dimensi tulangan di dalam beton juga kadang sulit dideteksi dengan peralatan yang ada di pasaran sekarang. Akan tetapi, kajian kerentanan gedung beton bertulang yang sudah berdiri tetap harus dilakukan karena hal ini dapat mengurangi risiko bencana gempabumi di daerah dengan risiko gempabumi sedang maupun tinggi.

\section{BAHAN DAN METODE}

\subsection{Bahan}

Bahan-bahan yang digunakan dalam penelitian ini adalah:

1. Standar SNI 1726:2012 mengenai Tatacara perencanaan ketahanan gempa untuk struktur bangunan gedung dan non gedung.

2. Standar SNI 1727:2013 mengenai Beban minimum untuk perancangan bangunan gedung dan struktur lain.

3. Standar SNI 2847:2013 mengenai Persyaratan beton struktural untuk bangunan gedung.

4. Gedung yang sudah terbangun (struktur gedung beton bertulang).

5. Gambar As Built Drawing struktur gedung (gambar harus diadakan oleh pengelola gedung).

Alat-alat yang digunakan dalam penelitian ini adalah:

1. Alat uji kuat tekan beton di lapangan berupa Hammer Test (dan Ultrasonic Pulse Velocity Tester jika ada).

2. Alat pemindai tulangan dalam beton berupa Profometer (dikombinasi dengan Geo-penetrating Radar jika ada).

3. Alat pengukur dimensi berupa meteran, laser distometer, dan jangka sorong.

4. Perangkat lunak analisis struktur.

\subsection{Metode}

Metode yang digunakan dalam penelitian ini adalah pendetailan dari metode yang diusulkan di dalam subbab tujuan penelitian:

1. Survei di lapangan terdiri dari: a. Pengukuran dimensi struktur gedung pada kolom, balok, pelat lantai, dan dinding struktur dengan menggunakan meteran dan laser distometer.

b. Pengujian kuat tekan beton struktur gedung pada kolom, balok, pelat lantai, dan dinding struktur dengan menggunakan hammer test (dan Ultrasonic Pulse Velocity Tester jika ada)

c. Pemindaian dimensi baja tulangan di dalam kolom, balok, pelat lantai, dan dinding struktur dengan menggunakan profometer (dikombinasi dengan Geopenetrating Radar jika ada)

2. Analisis terdiri dari:

a. Hasil pengujian kuat tekan beton struktur gedung pada kolom, balok, pelat lantai, dan dinding struktur dilakukan analisis statistik untuk menentukan kuat tekan betonnya dalam satuan $\mathrm{kg} / \mathrm{cm}^{2}$ atau dalam Mega Pascal (MPa).

b. Hasil pemindaian dimensi baja tulangan di dalam kolom, balok, pelat lantai, dan dinding struktur dilakukan analisis untuk mendapatkan dimensi tulangan utama (longitudinal) baik jumlah maupun diameternya.

c. Nilai dimensi struktur, nilai kuat tekan beton, dan dimensi tulangan, dimasukkan dalam perangkat lunak analisis struktur untuk menghitung:

i. Ragam getar dan waktu getar alami struktur bangunan gedung sesuai standar (SNI 1726 2012).

ii. Kekuatan kolom dan balok sesuai dengan standar (SNI 2847 2013).

d. Perbandingan nilai:

i. Waktu getar alami struktur dibandingkan dengan waktu getar batas di dalam SNI 17262012.

ii. Kekuatan kolom dibandingkan dengan kekuatan balok sesuai dengan standar SNI 28472013.

e. Apabila hasil perbandingan menunjukkan nilai yang tidak sesuai, maka perlu dilakukan kajian rekomendasi yang paling sesuai untuk memperkuat struktur.

\section{HASIL DAN PEMBAHASAN}

\subsection{Survei Lapangan}

3.1.1. Gedung Kajian

Gedung yang dikaji terbuat dari material beton bertulang dengan bentuk yang dikategorikan tidak beraturan karena merupakan kombinasi dari gedung 8 lantai, 4 lantai, 3 lantai, dan ramp. 


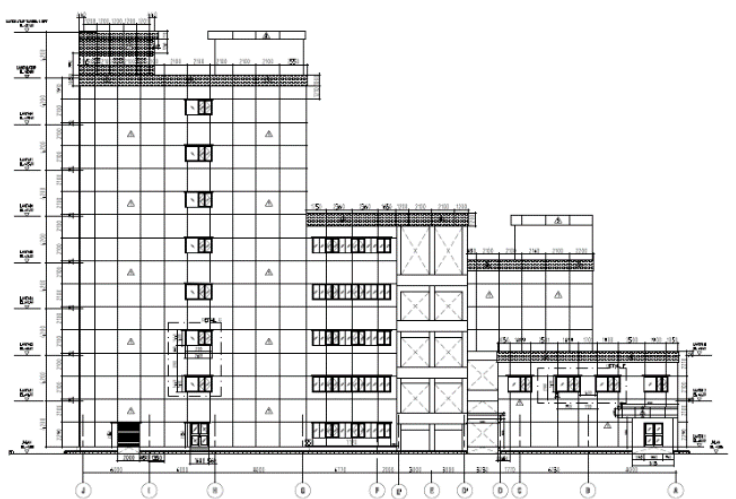

(a) Tampak depan

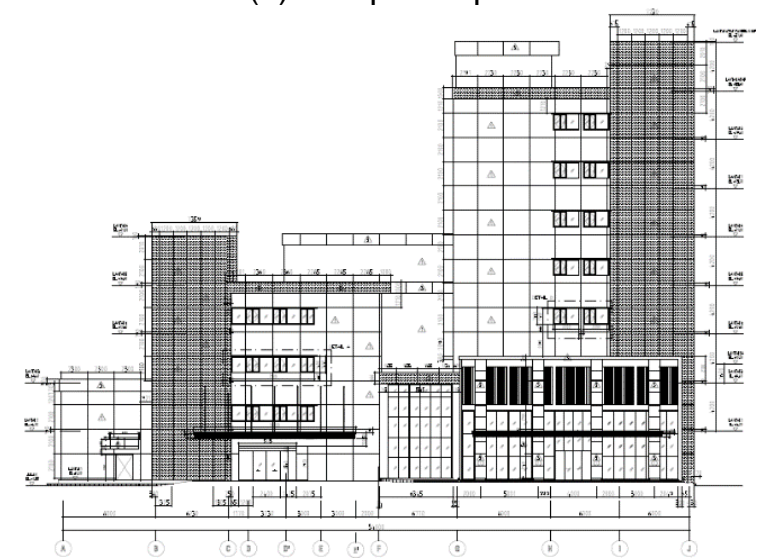

(b) Tampak belakang



(c) Tampak samping kanan

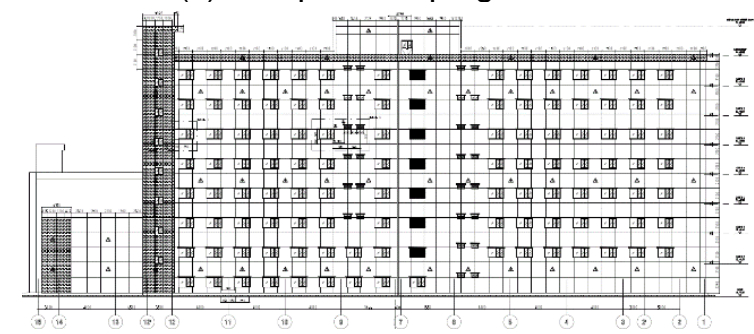

(d) Tampak samping kiri

Gambar 1. Tampak dari Gedung Kajian

(Hasil gambar ulang dari Gambar Arsitektur Gedung)

\subsubsection{Perolehan As Built Drawing}

Perolehan gambar struktur As Built Drawing merupakan hal yang paling penting dilakukan, namun belum tentu tersedia pada gedung yang sudah terbangun. Umumnya gambar ini jarang disimpan dengan baik oleh pengelola gedung. Berbeda dengan gambar mekanikal elektrikal atau gambar arsitektur ruangan yang lebih sering diperiksa kembali, gambar struktur lebih jarang dilihat-lihat lagi. Hal ini dikarenakan struktur dianggap sudah tidak akan diubah lagi, dan hanya menjadi penting manakala dilakukan perubahan struktur gedung, yang jarang sekali terjadi.

\subsubsection{Pengukuran Dimensi}

Pengukuran dimensi dilakukan pada kolom, balok, pelat lantai, dan dinding struktur. Juga dilakukan pengukuran pada tinggi antar lantai dan jarak antar kolom. Pada kondisi di mana ada beban tambahan yang signifikan, misalkan ada tangki air dan chiller AC, maka dilakukan pengukuran pada dimensi dan material beban.

\subsubsection{Pengujian Kuat Tekan Beton}

Pengujian kuat tekan beton dilakukan pada permukaan beton kolom, balok, pelat lantai, dan dinding struktur yang tidak tertutup plesteran maupun penutup lainnya. Sebelum dilakukan uji nilai pantul dengan alat hammer test, permukaannya juga harus dihaluskan dulu dengan amplas beton, agar hasilnya tidak terlalu rendah. Nilai pantul yang terlalu menyimpang (outlayer) diabaikan, kemudian 10 nilai pantul (tanpa outlayer) dirata-ratakan. Hasil rata-rata dikonversikan ke kuat tekan kubus beton dalam satuan $\mathrm{kg} / \mathrm{cm}^{2}$, atau kuat tekan silinder beton dalam satuan MPa (Mega Pascal).

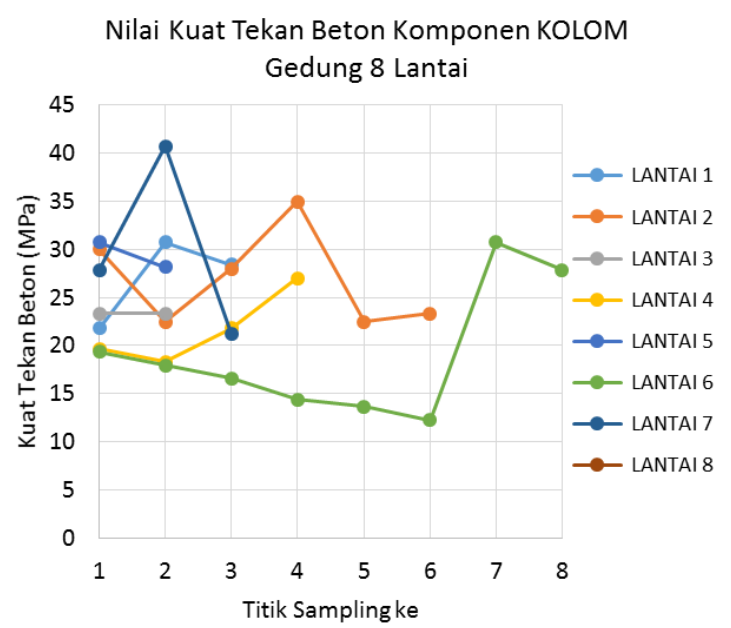

Gambar 2. Hasil Uji Kuat Tekan Beton pada Kolom di Gedung 8 Lantai

\subsubsection{Pemindaian Baja Tulangan}

Pemindaian baja tulangan di dalam beton dilakukan pada kolom, balok, pelat lantai, dan dinding struktur. Pemindaian perlu dilakukan secara berulang kali pada kolom yang sama, karena posisi tulangan dan ketebalan selimut beton menentukan keberhasilan dalam mendapatkan nilai dimensi tulangan yang tepat. 




Gambar 3. Hasil Pemindaian berupa

Penyebaran Tulangan dalam Penampang Kolom

Tabel 1. Dimensi Tulangan dalam Penampang Kolom

\begin{tabular}{|c|c|c|c|c|c|c|}
\hline \multirow{2}{*}{$\begin{array}{c}\text { Tipe } \\
\text { Kolom }\end{array}$} & $\begin{array}{c}\text { Dimen } \\
\mathrm{si} \\
(\mathrm{H} \times \mathrm{A})\end{array}$ & \multicolumn{2}{|c|}{$\begin{array}{c}\text { Jumlah } \\
\text { Tulangan }\end{array}$} & \multirow{2}{*}{$\begin{array}{c}\text { Dia- } \\
\text { meter }\end{array}$} & $\begin{array}{c}\text { Rasio } \\
\text { Tulang } \\
\text { an }\end{array}$ & $\begin{array}{c}\text { Seli- } \\
\text { mut } \\
\text { Beton } \\
(\mathrm{mm})\end{array}$ \\
\hline $\mathrm{K} 1$ & $70 \times 70$ & 5 & 5 & 40 & 0.04 & 35 \\
\hline $\mathrm{K} 2$ & $55 \times 65$ & 3 & 4 & 40 & 0.04 & 46 \\
\hline $\mathrm{K} 3$ & $50 \times 60$ & 4 & 4 & 40 & 0.05 & 39 \\
\hline $\mathrm{K} 4$ & $75 \times 60$ & 5 & 4 & 40 & 0.04 & 36 \\
\hline $\mathrm{K} 5$ & $\mathrm{D} 70$ & $16 \mathrm{D} 32$ & 32 & 0.03 & \\
\hline $\mathrm{K} 6$ & $60 \times 40$ & 3 & 3 & 32 & 0.03 & 49 \\
\hline $\mathrm{K} 7$ & $40 \times 60$ & 3 & 3 & 40 & 0.04 & 59 \\
\hline $\mathrm{K} 8$ & $40 \times 40$ & 3 & 3 & 32 & 0.04 & 34 \\
\hline $\mathrm{K} 9$ & $45 \times 65$ & 3 & 4 & 40 & 0.04 & 50 \\
\hline $\mathrm{K} 10$ & $45 \times 85$ & 3 & 5 & 40 & 0.04 & 57 \\
\hline $\mathrm{K} 1 \mathrm{P}(\mathrm{A})$ & $85 \times 80$ & 6 & 6 & 40 & 0.04 & 49 \\
\hline $\mathrm{K} 1 \mathrm{P}(\mathrm{B})$ & $90 \times 80$ & 6 & 6 & 40 & 0.03 & 35 \\
\hline $\mathrm{K} 4 \mathrm{P}(\mathrm{A})$ & $80 \times 60$ & 5 & 4 & 40 & 0.04 & 60 \\
\hline $\mathrm{K} 4 \mathrm{P}(\mathrm{B})$ & $75 \times 60$ & 5 & 4 & 40 & 0.04 & 59 \\
\hline
\end{tabular}

\subsubsection{Pemodelan Struktur Gedung}

Pemodelan struktur gedung dilakukan menggunakan perangkat lunak analisis struktur. Data-data yang dimasukkan terdiri dari:

1. Dimensi struktur gedung.

2. Kuat tekan beton.

3. Dimensi tulangan dalam komponen struktur (kolom, balok, lantai, dan dinding struktur).

4. Beban mati, beban hidup, beban gempa, yang sesuai dengan standar yang berlaku (SNI 1727: 2013).

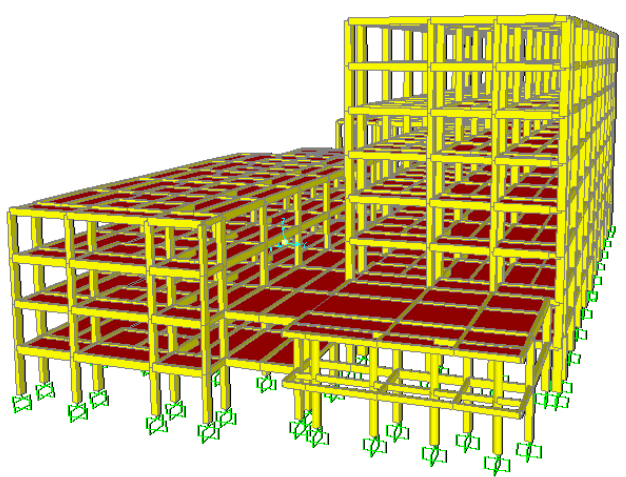

(a)

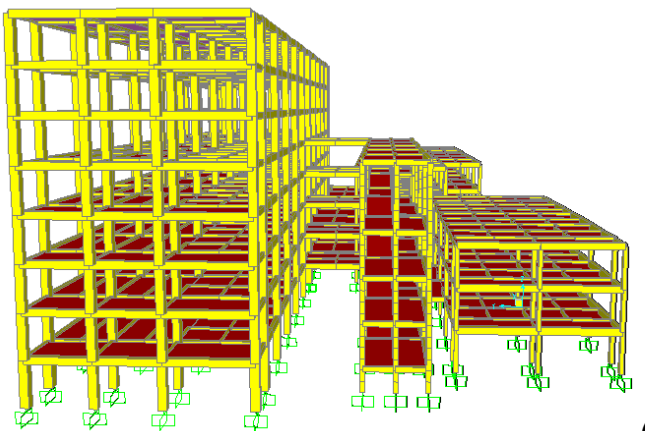

(b)

Gambar 4. Model Numerik Struktur Gedung

(a) Tampak Depan (b) Tampak Belakang

\subsubsection{Analisis Kekuatan Struktur Gedung}

Setelah dilakukan pemodelan struktur, maka dilakukan analisis:

1. Analisis sifat getar struktur yaitu:

a. Ragam getar

b. Perioda Getar Fundamental Struktur

2. Kapasitas komponen struktur (kolom, balok, pelat lantai, dan dinding struktur)

3. Gaya-gaya yang terjadi pada akibat beban hidup, beban mati, dan beban gempa

4. Perbandingan antara kapasitas komponen struktur dengan gaya-gaya yang terjadi akibat beban gempa.

Di dalam SNI 17262012 (Badan Standardisasi Nasional, 2012) disebutkan bahwa perioda getar fundamental struktur, $T$, tidak boleh melebihi batasan atas pada perioda fundamental pendekatan, Ta. Dengan kata lain, struktur tidak boleh terlalu lentur.

Perioda Fundamental Struktur, T, tidak boleh melebihi hasil koefisien untuk batasan atas pada perioda yang dihitung, $\mathrm{Cu}$ dan perioda fundamental pendekatan, Ta. Cu ditentukan dari Tabel 2 dan $\mathrm{Ta}$ ditentukan sesuai dengan Persamaan (1).

Tabel 2. Koefisien untuk Batas Atas Perioda Getar

\begin{tabular}{|c|c|}
\hline $\begin{array}{c}\text { Parameter Percepatan } \\
\text { Spektral Response Desain } \\
\text { pada 1 detik, } S_{D 1}\end{array}$ & Koefisien $\mathrm{Cu}$ \\
\hline$\geq 0,4$ & 1,4 \\
\hline
\end{tabular}




\begin{tabular}{|c|c|}
\hline 0,3 & 1,4 \\
\hline 0,2 & 1,5 \\
\hline 0,15 & 1,6 \\
\hline$\leq 0,1$ & 1,7 \\
\hline
\end{tabular}

Di mana:

$$
T_{a}=C_{t} h_{n}^{x}
$$

$h_{n} \quad:$ ketinggian struktur

$C_{t}$ dan $x$ adalah : lihat Tabel 3 .

Tabel 3. Koefisien $C_{t}$ dan $x$

\begin{tabular}{|l|c|c|}
\hline \multicolumn{1}{|c|}{ Tipe Struktur } & $C_{t}$ & $x$ \\
\hline Rangka baja pemikul momen & 0,0724 & 0,8 \\
\hline Rangka beton pemikul momen & 0,0466 & 0,9 \\
\hline $\begin{array}{l}\text { Rangka baja dengan bresing } \\
\text { eksentris }\end{array}$ & 0,0731 & 0,75 \\
\hline $\begin{array}{l}\text { Rangka baja dengan bresing } \\
\text { terkekang terhadap tekuk }\end{array}$ & 0,0731 & 0,75 \\
\hline Semua sistem struktur lainnya & 0,0488 & 0,75 \\
\hline
\end{tabular}

Untuk kasus gedung kajian di atas, maka telah dihitung nilai batas atas periode getar dan nilai periode getar fundamental struktur berdasarkan perangkat lunak analisis struktur. Hasilnya ditunjukkan pada Gambar 5.

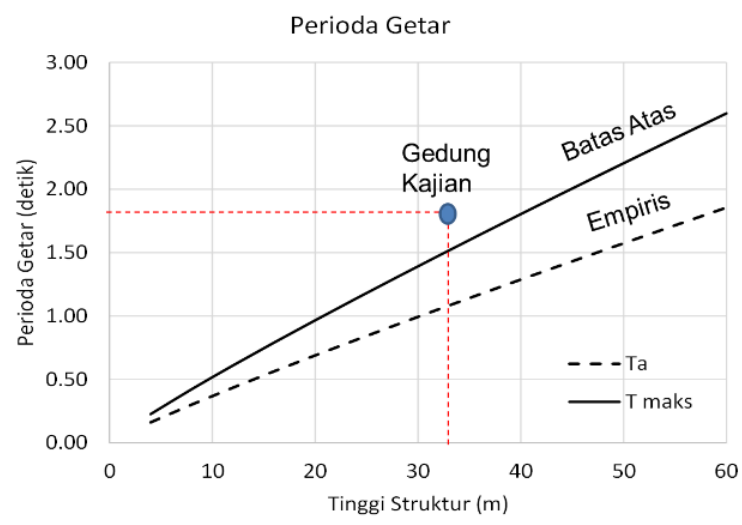

Gambar 5. Nilai Periode Getar Gedung Kajian Dibanding Nilai Batas Atas Periode Getar Pada SNI 1726:2012

Dari hasil di atas tampak bahwa gedung kajian memiliki periode getar fundamental melampaui batas atas yang dipersyaratkan di dalam SNI 1726:2012. Dengan kata lain, struktur terlalu lentur, sehingga harus diperkaku. Metode-metode pengakuan struktur dibahas di sub bab berikutnya.

Di dalam SNI 2847:2013 (Badan Standardisasi Nasional, 2013) disebutkan bahwa jumlah kekuatan lentur nominal kolom yang merangka ke dalam joint harus paling tidak sama dengan 1,2 kali jumlah kekuatan lentur nominal balok yang merangka ke dalam joint yang sama (Persamaan 2).

$$
\sum M_{n c} \geq(1,2) \sum M_{n b}
$$

Di mana:

$M_{n c}$ : jumlah kekuatan lentur nominal kolom yang merangka ke dalam join

$M_{n b}$ : jumlah kekuatan lentur nominal balok yang merangka ke dalam join



Gambar 6. Penamaan Variabel Kapasitas Kolom dan Balok Pada Join yang Sama
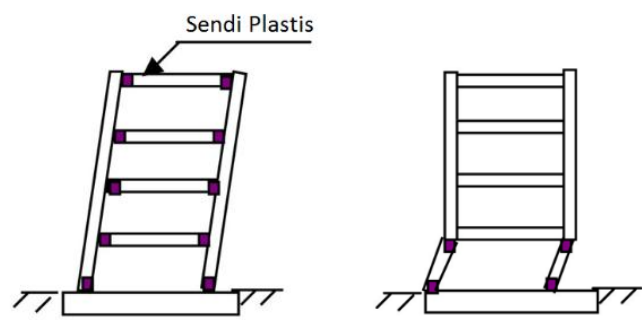

(a)

(b)

Gambar 7. Konsep Struktur Daktail

(a) Kolom kuat - Balok lemah

(b) Kolom lemah - Balok kuat

Jika terjadi percepatan gempabumi yang melampaui percepatan desain sehingga kapasitas struktur terlampaui, maka ada dua jenis kondisi kerusakan yang terjadi. Yang pertama, kondisi di mana kerusakan dilokalisir hanya pada sendi plastis di dasar kolom dan pada balok (Gambar 7.a). Kerusakan jenis ini akan menjaga struktur tetap berdiri walaupun mengalami kerusakan. Pendetilan yang sesuai standar untuk kolom dan balok dapat membuat struktur mengalami kerusakan seperti ini. Yang kedua, kondisi di mana kerusakan terjadi tidak hanya di dasar kolom saja (Gambar 7.b). Tidak adanya perencanaan yang sesuai standar, akan mengakibatkan kerusakan struktur seperti ini. Kerusakan ini mengakibatkan struktur mengalami soft story, yang mengakibatkan struktur runtuh.

Berdasarkan kajian pada gedung ini, pada gedung yang 3 lantai, maka ada kondisi di mana balok B1 dan kolom K8 bertemu di join yang sama (Gambar 8). Penampang balok B1 tampak pada Gambar 9.a. Nilai B = 
$35 \mathrm{~cm}$ dan $\mathrm{H}=70 \mathrm{~cm}$. Penampang kolom $\mathrm{K} 8$ dapat dilihat di Gambar 9.b. Lebar sisi-sisi kolom adalah masing-masing $40 \mathrm{~cm}$.

Kekuatan lentur nominal balok B1 $=645$ kN.m sedangkan kekuatan lentur nominal kolom $\mathrm{K} 8=275 \mathrm{kN} . \mathrm{m}$. Maka berdasarkan persamaan di bawah, $1,2 \sum M_{n b}$ lebih besar dari $\sum M_{n c}$. Hal ini tidak memenuhi syarat di dalam SNI 2847:2013. Hal seperti ini dapat terjadi, karena struktur gedung 3 lantai yang dikaji ini mempunyai bentang yang besar, 8 meter, sedangkan jumlah lantai gedung tidak banyak, hanya 3 lantai. Yang kemudian terjadi adalah kolom didesain cukup kecil, karena memang beban pada kolom relatif kecil. Hanya saja, jika terjadi gempa besar yang dapat membuat kapasitas kolom terlampaui, maka yang akan rusak terlebih dahulu adalah kolom. Kejadian ini dapat menyebabkan mekansisme soft story dan mengakibatkan keruntuhan struktur gedung.

$$
\begin{gathered}
\sum M_{n c}=275+275=550 \mathrm{kN} \cdot \mathrm{m} \\
1,2 \sum M_{n b}=1,2(645+645)=1548 \mathrm{kN} \cdot \mathrm{m}
\end{gathered}
$$

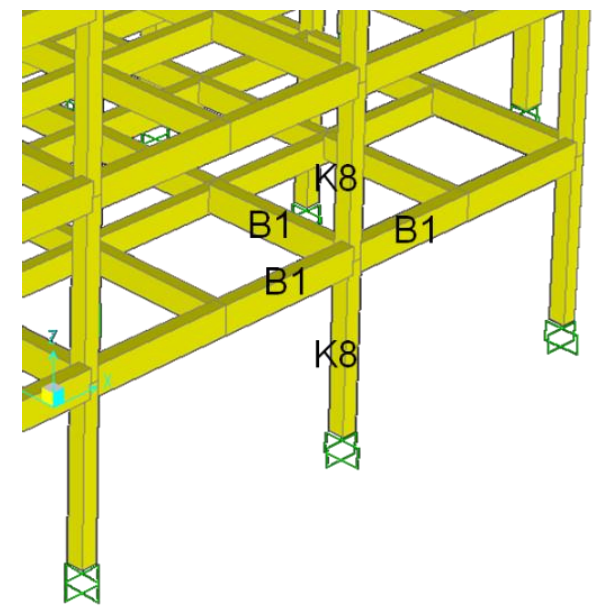

Gambar 8. Kolom dan Balok yang Bertemu Pada Satu Join Pada Gedung 3 Lantai

Di dalam SNI 2847:2013 juga disebutkan bahwa dimensi kolom yang sejajar terhadap tulangan balok (yang menumpu pada kolom tersebut) tidak boleh kurang dari 20 kali diameter batang tulangan balok longitudinal terbesar untuk beton normal. Hal ini akan memberikan konsekuensi sebagai berikut.



(a)

(b)

Gambar 9. (a) Penampang Balok B1 dan (b) Penampang Kolom K8

Balok beton B1 pada join di atas mempunyai tulangan seperti ditunjukkan pada Gambar 9a. Pada gambar tersebut, diameter tulangan terbesar pada balok adalah $22 \mathrm{~mm}$. Dengan kondisi ini, maka dimensi lebar kolom pada join yang sama dan sejajar dengan balok ini seharusnya mempunyai dimensi $20 \times 22=$ $440 \mathrm{~mm}$ atau $44 \mathrm{~cm}$. Pada kenyataannya, dimensi kolom K8 mempunyai dimensi lebar kolom sebesar $40 \mathrm{~cm}$. Jadi syarat pada SNI 2847:2013 tidak terpenuhi. Maksud dari adanya pembatasan ini adalah untuk memastikan bahwa tulangan balok dapat terangkur dengan sempurna pada kolom, sehingga join (sambungan) kolom-balok tidak mengalami kerusakan saat terjadi beban gempa yang berlebih. Kerusakan seharusnya terjadi pada balok saja.

\subsubsection{Kajian Perkuatan Struktur Gedung}

Berdasarkan analisis di atas, ada bagian gedung yang tidak memenuhi persyaratan SNI 1726:2012 maupun SNI 2847:2013. Gedung terlalu lentur untuk gedung 8 lantai dan kolom terlalu kecil untuk gedung 3 lantai. Oleh sebab itu, perlu dilakukan kajian terhadap metode-metode perkuatan struktur gedung. Secara garis besar, metode perkuatan terdiri dari:

1. Peningkatan kekuatan komponen tertentu struktur, misalnya dengan menambahkan struktur tambahan pada komponen tertentu.

2. Peningkatan kemampuan peredaman energi getaran struktur, misalnya dengan menambahkan supplemental damper pada gedung.

3. Penjauhan periode getar struktur dari periode getar dominan gempa di lokasi gedung, misalnya dengan menambahkan base isolation pada pondasi struktur yang sudah berdiri (Kawamura et al., 2000).

4. Penggabungan ketiga metode di atas.

Metode yang dibahas dalam makalah ini adalah metode yang pertama, yaitu 
peningkatan kekuatan komponen tertentu, karena metode ini adalah yang paling murah untuk dilaksanakan. Terdapat juga beberapa kekurangan yang akan disampaikan dalam makalah ini.

Salah satu cara peningkatan kekuatan adalah dengan menambah rangka bresing (bracing) pada struktur gedung seperti ditunjukkan pada Gambar 10. Dengan penambahan ini, maka struktur akan menjadi lebih kaku dan juga beban lentur pada kolom sebagian akan ditopang oleh rangka bresing. Rangka bresing ini dapat dibuat dari material yang cukup kuat, misalnya baja atau material lain yang lebih ringan namun kuat. Penekanan adalah pada bentuk batang menyilang sehingga gaya lateral yang terjadi pada rangka bresing ditahan oleh gaya tarik dan tekan pada batang bresing. Untuk menghindari tekuk (buckling) pada batang tarik, maka batang tarik dapat dilingkupi dengan selongsong (buckling-retrained braced frame (NEHRP, 2013) yang dapat mencegah terjadinya tekuk.

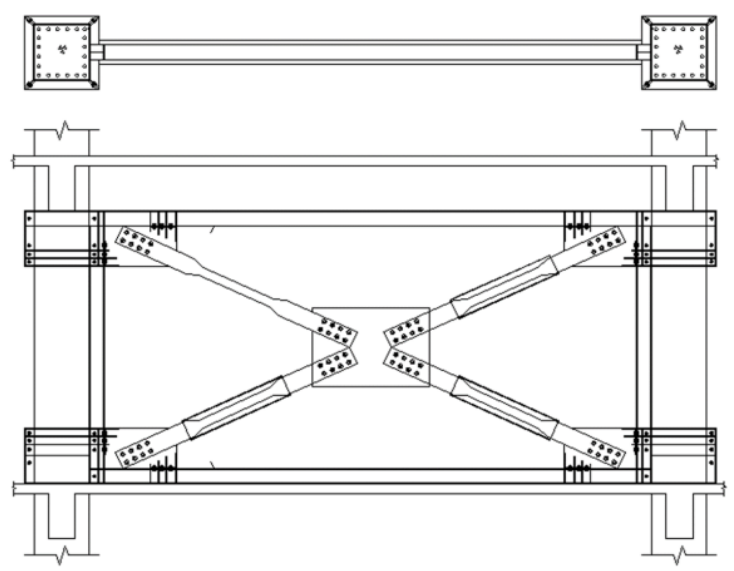

Gambar 10. Rangka Bresing (Bracing)

Tambahan yang Dikaji untuk Alternatif Perkuatan Struktur Gedung

Jika rangka bresing ditambahkan pada struktur rangka pemikul momen (SRPM), maka sebenarnya perilaku struktur berubah dari momen penahan gaya lateral menjadi gaya momen kopel tarik tekan kolom penahan gaya lateral gempabumi. Dengan kondisi demikian, maka kekuatan pondasi dapat menjadi faktor pembatas peningkatan kekuatan dengan penambahan rangka bresing ini. Pengecekan pada kekuatan pondasi diperlukan karena adanya tambahan gaya tekan dan tarik kolom, di mana penambahan gaya ini biasanya cukup signifikan.

Pada gedung kajian 3 lantai, penambahan rangka bresing pada beberapa lokasi (karena keterbatasan ruang yang bisa dipasangi rangka bresing) di lantai 1 sampai dengan lantai 3 ternyata untuk arah memanjang gedung, penambahan rangka bresing dibatasi oleh kekuatan pondasi yang sangat terbatas, sehingga peningkatan kekuatan antara sebelum dan sesudah penambahan tidak terlalu signifikan. Sedangkan pada arah melintang gedung, penambahan rangka bresing dapat meningkatkan kekuatan sampai hampir dua kali kekuatan tanpa rangka bresing, karena lokasi rangka bresing dapat ditumpu oleh pondasi yang lebih kuat.

\section{KESIMPULAN}

Berdasarkan kajian di atas, maka dapat disimpulkan hal-hal sebagai berikut:

1. Survei di lapangan terdiri dari:
a. Perolehan As Built Drawing.
b. Pengukuran dimensi.
c. Pengujian kuat tekan beton.
d. Pemindaian baja tulangan.

2. Analisis di kantor:

a. Analisis dimensi tulangan di dalam beton.

b. Analisis kuat tekan beton.

c. Analisis model numerik gedung.

d. Analisis waktu getar alami gedung dibandingkan dengan SNI 17262012.

e. Analisis kapasitas kolom dibandingkan dengan kapasitas balok sesuai dengan SNI 28472013.

f. Analisis dimensi kolom dibandingkan dengan dimensi tulangan balok sesuai denga SNI 28472013.

g. Analisis kapasitas struktur keseluruhan dibandingkan dengan gaya struktur akibat gempa sesuai dengan SNI 17262012.

h. Analisis metode peningkatan kekuatan struktur.

3. Hasil analisis pada gedung kajian:

a. Periode getar fundamental gedung 8 lantai lebih besar daripada batas atas periode getar fundamental, sehingga gedung 8 lantai ini perlu dilakukan peningkatan kekakuan struktur.

b. Jumlah kapasitas kolom pada gedung 3 lantai mempunyai nilai yang lebih kecil dibanding 1,2 kali jumlah kapasitas balok yang merangkai pada join yang sama, sehingga perlu dilakukan perkuatan pada kolom, karena kalau tidak, konsep kolom kuat balok lemah yang dipersyaratkan dalam SNI tidak bisa tercapai.

c. Dimensi lebar kolom pada gedung 3 lantai mempunyai nilai yang lebih kecil dari 20 kali diameter terbesar tulangan 
balok yang merangkai pada kolom, sehingga dikuatirkan tulangan balok tidak terangkur dengan sempurna pada kolom yang dapat mengakibatkan terjadinya kerusakan join balok-kolom.

4. Penerapan metode di atas, yang cukup langsung dan singkat dapat segera menunjukkan ketidaksesuaian suatu struktur terhadap persyaratan SNI untuk gedung tahan gempa. Metode ini diharapkan dapat diterapkan untuk gedung-gedung lain agar penilaian kesesuaian suatu struktur terhadap persyaratan SNI dapat dengan relatif mudah diterapkan.

5. Sebagai kelengkapan kajian, metode peningkatan perkuatan struktur agar lebih aman terhadap ancaman gempabumi juga ditunjukkan di sini. Dalam hal ini metode penambahan rangka bresing dapat digunakan. Akan tetapi ada hal-hal yang harus diperhatikan:

a. Dengan menambah rangka bresing, maka perilaku struktur berubah dari momen penahan gaya lateral, menjadi gaya momen kopel tarik tekan kolom penahan gaya lateral gempabumi.

b. Dengan kondisi di atas, kekuatan pondasi menjadi faktor pembatas peningkatan kekuatan.

c. Pengecekan pada kekuatan pondasi diperlukan karena adanya tambahan gaya tekan dan tarik kolom, di mana penambahan gaya ini cukup signifikan.

\section{PERSANTUNAN}

Ucapan terima kasih disampaikan kepada rekan-rekan di Pusat Teknologi Reduksi Risiko Bencana - TPSA - BPPT yang membantu dalam perolehan data lapangan yang digunakan dalam analisis. Ucapan terima kasih juga disampaikan kepada Pemerintah Kota Tangerang yang memberikan ijin dalam mengkaji gedunggedung di Kota Tangerang.

\section{DAFTAR PUSTAKA}

Badan Standardisasi Nasional. 2012. SNI 1726:2012 Tatacara perencanaan ketahanan gempa untuk struktur bangunan gedung dan non gedung.

Badan Standardisasi Nasional. 2013. SNI 2847:2013 Persyaratan beton struktural untuk bangunan gedung.

Departemen Pekerjaan Umum. 2007. Pedoman Sertifikat Laik Fungsi Bangunan
Gedung, Peraturan Menteri Pekerjaan Umum, Nomor: 25/PRT/M/2007, Tanggal 9 Agustus.

Detik News. 2014. Digaji Rp 12 Juta, Ini Tugas Tim Ahli Bangunan Gedung yang Dilantik Ahok. [terhubung berkala]. https://news.detik.com/berita/2575865/diga ji-rp-12-juta-ini-tugas-tim-ahli-bangunangedung-yang-dilantik-ahok [07 Mei 2014]. 